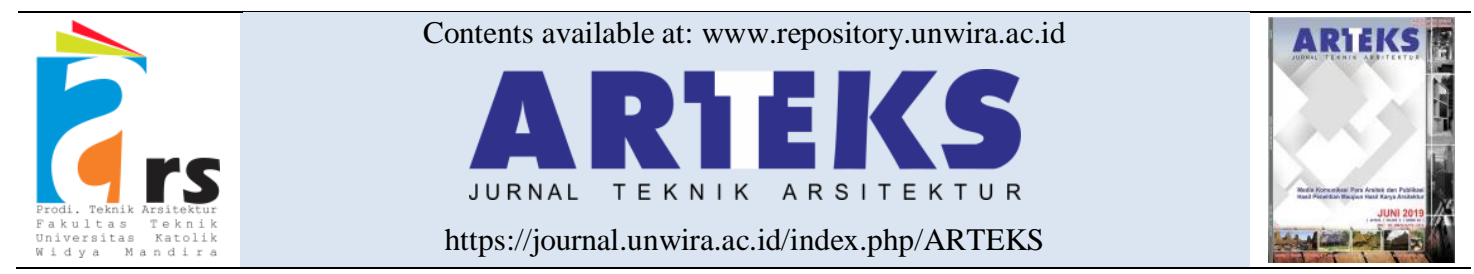

Research paper

doi: http://doi.org/10.30822/arteks.v4i1.79

\title{
Pelestarian Desa Hilinawalo Mazino di Kepulauan Nias sebagai destinasi wisata
}

\section{Anugerah Septiaman Harefa}

Program Studi Magister Arsitektur,

Fakultas Arsitektur dan Desain, Universitas Kristen Duta Wacana

Jl. dr. Wahidin Sudirohusodo 5 - 25, Yogyakarta, Indonesia

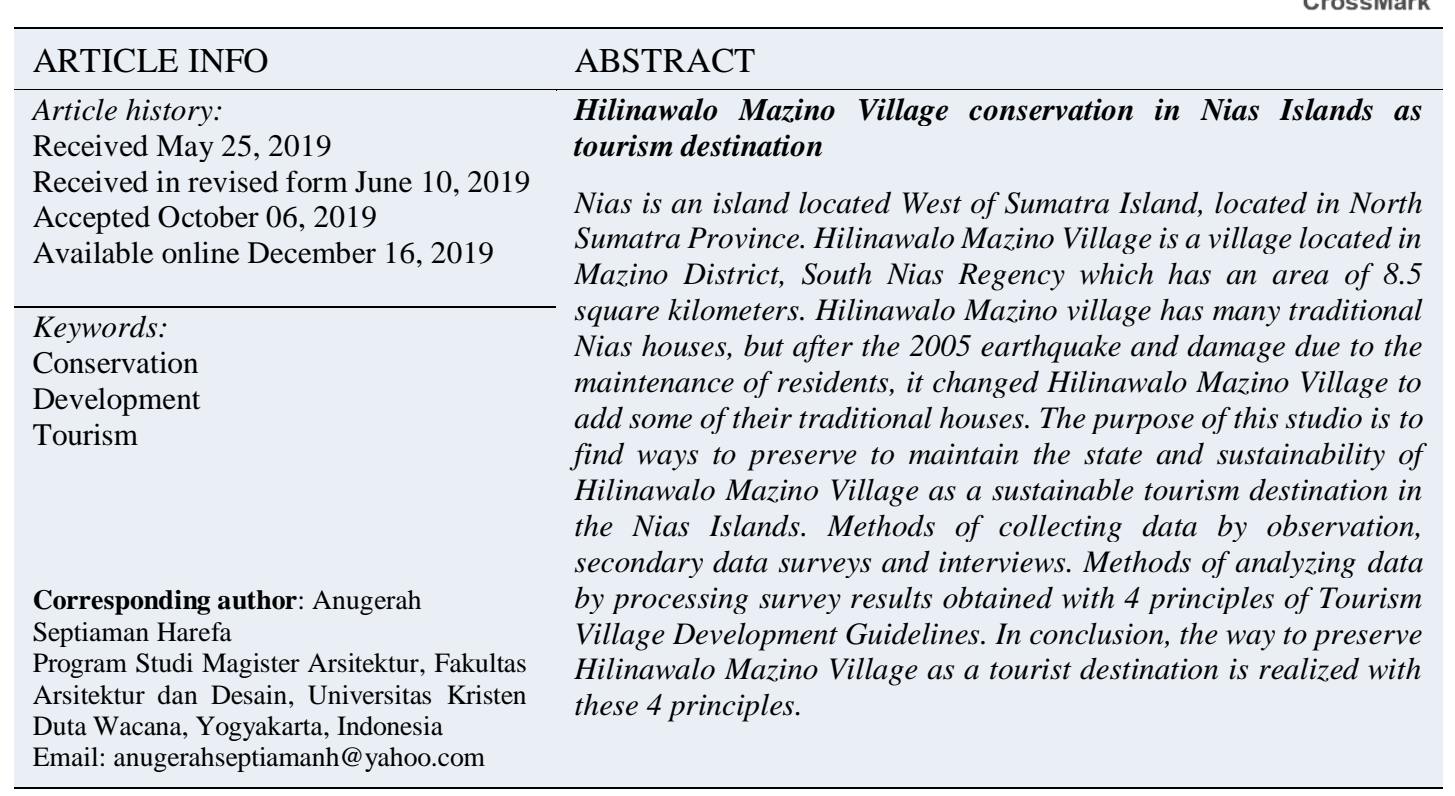

\section{Pendahuluan}

Nias merupakan pulau yang berada di sebelah Barat pulau Sumatera, tepatnya di Provinsi Sumatera Utara. Pulau ini terdiri atas satu kota dan 4 kabupaten yang baru mekar pada tahun 2009. Pulau Nias dikelilingi oleh laut dan keindahan alam lainnya.

Salah satu ciri khas dari Pulau Nias yang masih bisa dilihat hingga sampai saat ini adalah rumah adat Nias. Rumah adat Nias sering disebut dalam bahasanya sebagai omo hada (Bramantyo 2012). Keberadaan omo hada perlu untuk dipertahankan dan dilestarikan (Syuaib Intan and Nasruddin 2019). Masyarakat Nias yang memiliki kebiasaan berperang, mendirikan bangunannya sedemikian rupa, sehingga hunian bagi masyarakat Nias adalah sebagai shelter sekaligus benteng yang melindungi diri dari cuaca, binatang buas dan sekaligus musuh.

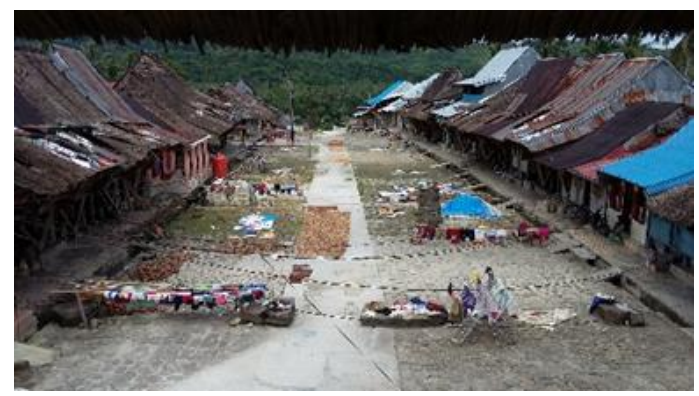

Gambar 1. Desa Hilinawalo Mazino

Kekerabatan yang erat, menciptakan hunian yang rapat antara rumah yang satu dengan 
lainnya, sehingga membentuk suatu pola linier yang memanjang, gerbang tidak begitu jelas dan halaman terdiri dari tanah yang diperkeras.

Rumah adat Nias Selatan yang berbentuk segi empat jumlahnya lebih banyak dibanding rumah adat Nias lainnya. Bawomataluo, Hilizalootano, Hilinawalo Mazingo dan masih banyak desa lain merupakan desa adat di Kabupaten Nias Selatan yang masih lestari. Desa Hilinawalo Mazino merupakan desa yang berada di Kecamatan Mazino, Kabupaten Nias Selatan dengan luas 8,5kilometer persegi.

Desa Hilinawalo Mazino jaraknya tidak terlalu jauh dari Ibu Kota Nias Selatan, sehingga menjadi destinasi wisata yang mudah untuk dikunjungi. Menurut Undang-Undang Republik Indonesia nomor 9 tahun 1990 tentang Kepariwisataan, "wisata adalah kegiatan perjalanan atau sebagian dari kegiatan tersebut yang dilakukan secara sukarela serta bersifat sementara untuk menikmati objek dan daya tarik wisata" serta Undang-Undang Republik Indonesia nomor 9 tahun 1990 tentang Kepariwisataan, "pariwisata adalah segala sesuatu yang berhubungan dengan wisata, termasuk pengusahaan objek dan daya tarik wisata serta usaha yang terkait di bidang tersebut" (Presiden Republik Indonesia 1990). Desa Hilinawalo Mazino berusia lebih 300 tahun dan lebih tua dari desa bawomataluo yang saat ini telah menjadi salah satu warisan budaya dunia yang telah diusulkan oleh UNESCO sejak tahun 2009 dan pada bulan Desember 2012 lalu, dianugerahi sebagai salah satu Wonder of the World from Indonesia oleh The Real Wonder of the World Foundation (Gea 2013), sehingga Desa Hilinawalo juga sangat tepat untuk dilestarikan, dan keberadaannya bisa juga diakui oleh dunia.

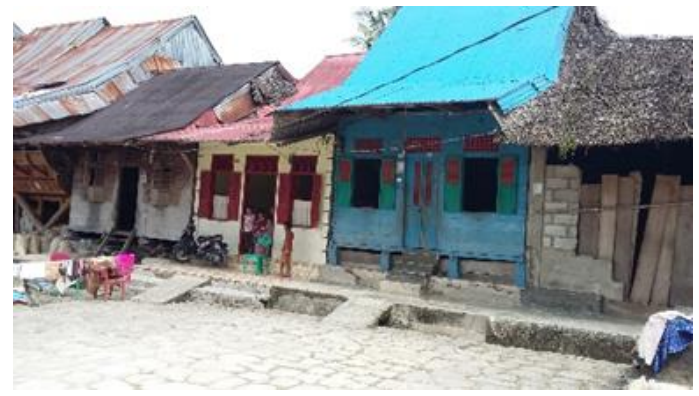

Gambar 2. Rumah adat yang telah berubah

Namun setelah terjadinya gempa pada tahun 2005 dan kerusakan karena kurangnya perawatan, hingga mengakibatkan Desa Hilinawalo Mazino kehilangan beberapa rumah adat ('Rumah Adat (Omo Lasara/Omo Hada) Hilinawalo Mazino' 2014). Namun semakin berkembangnya zaman, tentunya mengakibatkan perubahan-perubahan di Desa Hilinawalo Mazino, seperti perpindahan masyarakat asli ke kota, meninggalkan rumah adat tanpa perawatan dan banyaknya bangunan baru yang dibangun bukan dengan ciri khas rumah adat Nias, sehingga sangat perlu untuk dilakukan pelestarian. Menurut Kamus Besar Bahasa Indonesia, pelestarian berarti "proses atau cara, perbuatan melestarikan; perlindungan dari kemusnahan atau kerusakan, pengawetan, konservasi sumber-sumber alam, pengelolaan sumber daya alam yang menjamin pemanfaatannya secara bijaksana dan menjamin kesinambungan persediaannya dengan tetap memelihara dan meningkatkan kualitas nilai dan keanekaragamannya" (Pusat Bahasa Kemdikbud 2016), sehingga tetap menjadi suatu destinasi wisata yang berkelanjutan di Kepulauan Nias. Dengan melihat latar belakang permasalahan maka dirumuskan permasalahan sebagai berikut: Akibat dari gempa tahun 2005 dan kurangnya perawatan, dan dibangunannya bangunan baru yang dibangun bukan dengan ciri khas rumah adat Nias sehingga Desa Hilinawalo Mazino kehilangan banyak rumah adat. Tujuan studi ini ialah menemukan cara pelestarian untuk mempertahakan keadaan dan kelestarian Desa Hilinawalo Mazino sebagai destinasi wisata di Kepulauan Nias.

\section{Metode penelitian}

Studi ini menggunakan metode kualitatif dan pendekatan naratif. Untuk pengumpulan data dilakukan dengan observasi, survey data sekunder dan wawancara. Observasi fisik dengan merekam secara video maupun foto tentang keadaan Desa Hilinawalo Mazino dan lingkungannya. Data sekunder digunakan untuk menunjang proses studi dan wawancara dilakukan kepada ketua adat dan warga sekitar. Selain penelusuran data berdasarkan hasil wawancara, penelusuran studi banding dari library search juga dilakukan, seperti perbandingan kajian yang dilakukan oleh Purbadi dan Lake dengan judul Konsep-Wisata Sejahtera, Kreatif, Cerdas dan Lestari Berkelanjutan (Purbadi and Lake 2019; 'Pengembangan Masyarakat Untuk Pariwisata Di Kampung Wisata Toddabojo Provinsi Sulawesi 
Selatan' 2011); Konsep permukiman tradisional yang masih bertahan (Yuliana $\mathrm{K}$ and Kurniati 2013; Ritchi et al. 2018; Haiqal and Hidayat 2017; Lake et al. 2018; Salura and Lake 2014; Purbadi 2010; Mulyawardani and Septanti 2017; Lake 2014; Noor and Pratiwi 2016; Latupapua 2015; Lake 2015; Purbadi, Djunaedi, and Sudaryono 2019; Prasetyo 2019; Refranisa 2019; et al. 2014), sehingga data-data pustaka menjadi arahan dalam strategi dan arahan untuk menjawab masalah penelitin.

Metode menganalisis data yang digunakan adalah dengan mengolah hasil survei yang didapatkan dari 4 prinsip yang terdapat pada buku pedoman pengembangan desa wisata (Antara and Arida 2015).

\section{Temuan dan pembahasan}

Keadaan lingkungan Desa Hilinawalo Mazino yang terus mengalami perubahan tentunya harus tetap dilestarikan. Di bawah ini hasil survei dan pembahasan tentang pelestarian Desa Hilinawalo Mazino sebagai destinasi wisata melalui 4 prinsip yang terdapat pada buku pedoman, Sukma (2015). Pelestarian dapat dilakukan dengan penerapan konsep pembangunan di sektor pariwisata yang dikenal dengan konsep pembangunan pariwisata berkelanjutan (sustaniable tourism development), yang pada intinya mengandung pengertian pembangunan pariwisata yang tanggap terhadap minat wisatawan dan keterlibatan langsung dari masyarakat setempat dengan tetap menekankan upaya perlindungan dan pengelolaannya yang berorientasi jangka panjang, sehingga dapat mempertahankan keadaan Desa Hilinawalo Mazino. Menurut Sukma (2015), Konsep pembangunan pariwisata berkelanjutan tersebut pada intinya menekankan empat prinsip, yaitu (Antara and Arida 2015):

1. Layak secara ekonomi (economically feasible)

Prinsip economically feasible, menekankan bahwa proses pembangunan harus layak secara ekonomi, dilaksanakan secara efesien untuk dapat memberikan nilai manfaat ekonomi yang berarti baik bagi pembangunan wilayah maupun peningkatan kesejahteraan masyarakat local (Antara and Arida 2015). Sehingga, secara ekonomi Desa Hilinawalo Mazino yang telah menjadi warisan dunia memiliki nilai yang sangat tinggi untuk tetap bertahan secara ekonomi. Sektor ekonomi merupakan aspek yang penting, karena dengan terjaminnya ekonomi warga dari pelestarian Desa Hilinawalo Mazino, tentunya meningkatkan niat dan kesadaran warga untuk tetap mempertahakan keberlangsungan kehidupannya di tempat tersebut dan mempertahankan keadaan tempat tetap memiliki nilai alami dan berbudaya. Menurut Pendit (1986), pariwisata merupakan salah satu jenis industri baru yang mampu menghasilkan pertumbuhan ekonomi yang cepat disamping kegiatan untuk mendapatkan kenikmatan, mencari kepuasan, mengetahui sesuatu (Pendit 1999). Warga Desa Hilinawalo Mazino memiliki beberapa jenis pekerjaan yang bisa terus berkembang. Pekerjaan yang terdapat di Desa Hilinawalo Mazino berdasarkan hasil wawancara dan survei langsung yaitu mayoritas bekerja sebagai petani dan sisanya sebagai pengrajin souvenir, pedagang, atraksi lompat batu, pegawai negeri sipil, tukang bangunan dan para pemandu wisata.

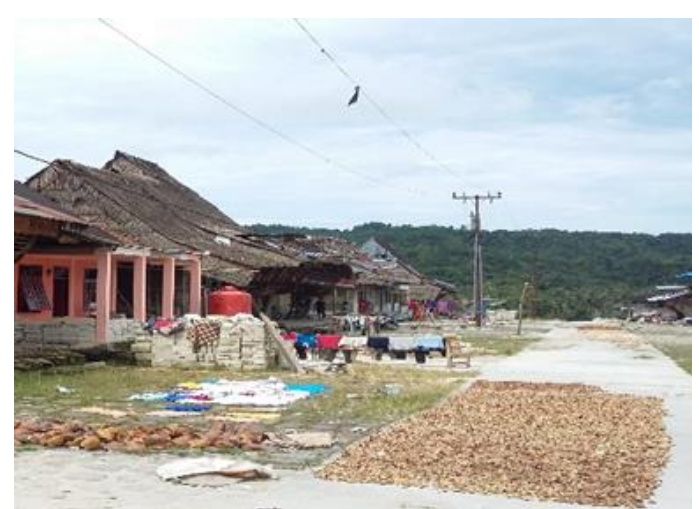

Gambar 3. Hasil pertanian penduduk

\section{Berwawasan lingkungan (environmentally} feasible)

Dalam hal lingkungan menekankan bahwa proses pembangunan harus tanggap dan memperhatikan upaya untuk menjaga kelestarian lingkungan (alam maupun budaya), dan seminimal mungkin menghindarkan dampak negatif yang dapat menurunkan kualitas lingkungan dan mengganggu keseimbangan ekologi (Antara and Arida 2015). Keadaan lingkungan Desa Hilinawalo Mazino berdasarkan pengamatan langsung secara umum masih terawat karena berada di atas bukit, dikelilingi oleh lingkungan yang masih alami, dan pepohonan rindang, namun tanpa adanya kesadaran dan perhatian dari warga, organisasi sosial serta pemerintah, tentunya keadaan yang sekarang bisa 
berubah dan menghilangkan ciri khas dari keadaan awal.

Kerusakan lingkungan, penebangan liar dan pencemaran lingkungan oleh sampah menjadi permasalahan yang paling besar menurut peneliti, sehingga perlu adanya edukasi, kesadaran kepada penduduk setempat agar tetap menjaga lingkungannya, peningkatan infrastruktur dan menjaga keadaan lingkungan.

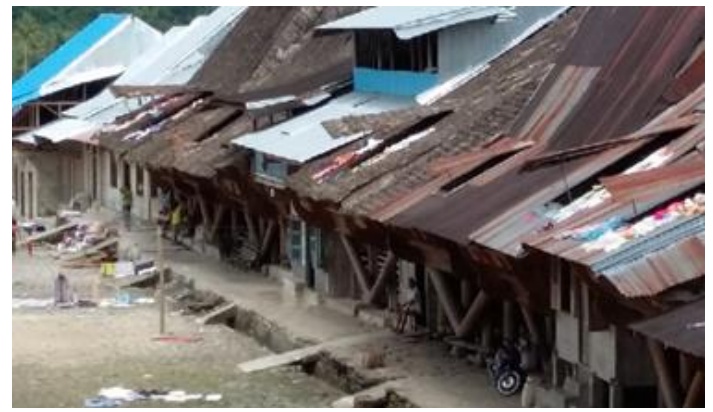

Gambar 4. Lingkungan Desa Hilinawalo Mazino

3. Dapat diterima secara sosial (socially acceptable)

Dapat diterima secara sosial yaitu menekankan bahwa proses pembangunan harus dapat diterima secara sosial, dimana upaya-upaya pembangunan yang dilaksanakan agar memperhatikan nilai-nilai, norma-norma yang ada dilingkungan masyarakat, dan bahwa dampak pembangunan tidak boleh merusak tatanan tersebut (Antara and Arida 2015).

Dalam proses pelestarian Desa Hilinawalo Mazino sebagai desa wisata, pembangunan yang dilakukan tentunya sangat mendukung semua aspek yang ada berdasarkan pengamatan langsung, keadaan Desa Hilinawalo Mazino yang masih menjunjung tinggi adat istiadat daerah perlu dipertahankan, pembangunan yang ada harus diterima secara sosial oleh warga, yang semuanya harus diterima secara adat istiadat Desa Hilinawalo Mazino sehingga tidak mengganggu tatanan yang sudah terbina dari dahulu. Tindakan yang perlu dilakukan secara sosial untuk mempertahakan kerberlanjutan yaitu rutin melakukan sosialisasi kepada masyarakat terutama generasi muda dan adanya pemberdayaan masyarakat Desa Hilinawalo Mazino sehingga lebih proaktif.

4. Dapat diterapkan secara teknologi (pechnologically appropriate).

Pembangunan dalam aspek teknologi menekankan bahwa proses pembangunan yang dilaksanakan secara teknis dapat diterapkan, efesien dan memanfaatkan sumberdaya lokal dan dapat diadopsi oleh masyarakat setempat secara mudah untuk proses pengelolaan yang berorientasi jangka panjang (Antara and Arida 2015). Aspek penting dalam pembangunan yaitu secara teknologi, dimana aspek teknologi ini yang membuat Desa Hilinawalo Mazino lebih bertahan dan berkembang di era seperti sekarang ini, dimana segala hal sangat berkaitan dengan teknologi. Seperti hasil survei di Desa Hilinawalo Mazino, pengetahuan warga terhadap teknologi masih sangat minim, sehingga untuk mengakses informasi dan mempromosikan hasil dari kerajinan tidak dapat dilakukan. Dalam proses ini, secara teknologi pelestarian Desa Hilinawalo Mazino bisa dilakukan dengan pelatihan penggunaan teknologi kepada warga, penggunaan material yang lebih baru untuk fisik bangunan, pembangunan sarana yang lebih efisien untuk lingkungan, sarana promosi, kemudahan dalam mengakses keberadaan lokasi oleh calon wisatawan dan dibuatnya website maupun aplikasi khusus Desa Hilinawalo Mazino.

\section{Kesimpulan}

Dari pembahasan di atas, dapat disimpulkan bahwa pelestarian Desa Hilinawalo Mazino sebagai destinasi wisata yang berkelanjutan dapat diwujudkan melalui pembangunan berdasarkan 4 prinsip menurut sukma (2015), karena semua aspek yang ada saat ini memenuhi untuk terus dikembangkan. Sehingga secara sederhana pembangunan pariwisata desa Hilinawalo Mazino dapat diwujudkankan dengan sasaran utama pencapaian, yaitu: (a) Secara ekonomi, sektor ekonomi merupakan aspek yang penting, karena dengan terjaminnya ekonomi warga dari pelestarian Desa Hilinawalo Mazino, tentunya meningkatkan niat dan kesadaran warga untuk tetap mempertahakan keberlangsungan kehidupan sosial masyarakat di tempat tersebut dan mempertahankan keadaan tempat secara alamiah dan berbudaya. Ada beberapa langkah pelestarian secara ekonomi yang bisa dilakukan yaitu: promosi hasil kerajinan, pengembangan bidang usaha dan memeberi modal serta festival budaya yang rutin; (b) Secara lingkungan yaitu kerusakan lingkungan, penebangan liar dan pencemaran lingkungan oleh sampah menjadi masalah paling besar yang dapat terjadi, sehingga dalam proses pelestarian hal yang dapat dilakukan 
yaitu: adanya edukasi, kesadaran masyarakat setempat agar tetap menjaga lingkungannya, dan peningkatan infrastruktur; (c) Secara sosial, keadaan Desa Hilinawalo Mazino yang masih menjunjung tinggi adat istiadat daerah perlu dipertahankan, pembangunan yang ada harus diterima secara sosial oleh warga, dalam proses pelestarian, hal yang dapat dilakukan yaitu: melakukan sosialisasi kepada masyarakat terutama generasi muda dan adanya pemberdayaan masyarakat Desa Hilinawalo Mazino, sehingga lebih proaktif; (d) Secara teknologi yakni aspek penting dalam mempertahankan keberlangsungan desa pariwisata baik sistem komunikasi maupun informasi akan keberadaan Desa Hilinawalo Mazino, sehingga lebih bertahan dan berkembang di era seperti sekarang ini. Dalam proses pelestarian, hal yang dapat dilakukan yaitu: pelatihan penggunaan teknologi kepada warga, penggunaan material yang lebih baru untuk material bangunan, pembangunan sarana yang lebih efisien untuk lingkungan, sarana promosi, kemudahan dalam mengakses keberadaan lokasi oleh calon wisatawan dan adanya website maupun aplikasi khusus wisata Desa Hilinawalo Mazino. Sehingga dengan melakukan pembangunan terhadap 4 prinsip di atas, pelestarian Desa Hilinawalo Mazino sebagai destinasi wisata di Kepulauan Nias dapat diwujudkan.

Saran yang bisa disampaikan: kiranya Pemerintah Daerah dan Lembaga Swadaya Masyarakat (LSM) dapat bersama-sama memberikan perhatian terhadap pelestarian Desa Hilinawalo Mazino melalui pembangunan 4 aspek yaitu ekonomi, lingkungan, sosial dan teknologi. Dengan demikian, pelestarian Desa Hilinawalo Mazino dapat dipertahankan dan diwujudkan serta menjadi destinasi wisata di Kepulauan Nias.

\section{Referensi}

Antara, Made, and Sukma Arida. 2015. 'Panduan Pengeloaan Desa Wisata Berbasis Potensi Lokal'.

Bali. https://simdos.unud.ac.id/uploads/file_penelit ian_1_dir/bb9746610f49ba39f27856edb9536 2f9.pdf.

Bramantyo. 2012. 'Identifikasi Arsitektur Rumah Tradisional Nias Selatan Dan Perubahannya'. Jurnal Permukiman 7 (3): 151-61.
Gea, Yafaowoloo. 2013. 'Bawomataluo, Warisan Budaya Dunia Di Bukit Matahari'. Kompasiana Beyond Blogging. 2013. https://www.kompasiana.com/java05_gheeya hoo.com/551f8e33813311f3379df266/bawo mataluo-warisan-budaya-dunia-di-bukitmatahari.

Haiqal, Moch. Khalif, and Syarip Hidayat. 2017. 'PENERAPAN IDENTITAS VISUAL PADA MEDIA PROMOSI WEBSITE WISATA KERAJINAN RAJAPOLAH'. Desain Komunikasi Visual, Manajemen Desain Dan Periklanan (Demandia). https://doi.org/10.25124/demandia.v2i02.934.

Lake, Reginaldo Christophori. 2014. 'Konsep Ruang Dalam Dan Ruang Luar Arsitektur Permukiman Tradisional Suku Atoni Di Kampung Adat Tamkesi Di Pulau Timor'. Universitas Katolik Parahyangan.

- 2015. 'Budaya Tektonika Wologai Ende, Nusa Tenggara Timur Sebuah Seni Berkonstruksi Rumah Adat Desa Wologai Tengah, Kecamatan Detusoko, Warisan Leluhur Wawo - Ata Lio Di Bawah Kaki Gunung Lepembusu'. ATRIUM: Jurnal Arsitektur 1 (2): 151-66. https://doi.org/10.21460/atvm.2016.12.15.

Lake, Reginaldo Christophori, Benediktus Boli, Ubaldus Djonda, and Yohanes Nurak Siwa. 2018. 'Building Task Concepts of the Vernacular Settlement in Tamkesi Village'. In IOP Conference Series: Earth and Environmental Science. https://doi.org/10.1088/17551315/213/1/012034.

Latupapua, Yosevita Th. 2015. 'Implementasi Peran Stake Holder Dalam Pengembangan Ekowisata Di Taman Nasional Manusela (TNM) Di Kabupaten Maluku Tengah'. Jurnal Agroforestri.

Mulyawardani, Ranti Amalia, and Dewi Septanti. 2017. 'Wisata Edukasi Dan Rekreasi Di Kawasan Sungai Cisadane'. Jurnal Sains Dan Seni ITS. https://doi.org/10.12962/j23373520.v6i2.272 25.

Nasution, Meyga Fitri Handayani, and Dharma Widya. 2014. 'Pelestarian Kawasan Tanjung Pura Sebagai Aset Wisata Di Kabupaten Langkat'. Review of Urbanism and Architectural Studies. https://doi.org/10.21776/ub.ruas.2014.012.02. 3.

Noor, Any Ariany, and Dea Rizky Pratiwi. 2016. 
'Konsep Pengembangan Pariwisata Berkelanjutan Di Kampung Buyut Cipageran ( Kabuci ) Kota Cimahi'. JURNAL 7th Industrial Research, Workshop, and National Seminar.

Pendit, Nyoman S. 1999. Ilmu Pariwisata, Sebuah Pengantar Perdana. Jakarta: Pradnya Paramita.

'Pengembangan Masyarakat Untuk Pariwisata Di Kampung Wisata Toddabojo Provinsi Sulawesi Selatan'. 2011. Journal of Regional and City Planning.

Prasetyo, V. F. Agung Langgeng. 2019. 'Tradisi Pada Rumah Adat Suku Ngalum Ok Di Era Modernisasi'. ARTEKS: Jurnal Teknik $\begin{array}{llll}\text { Arsitektur } & 3 & \text { (2): } & \text { 187-98. }\end{array}$ https://doi.org/10.30822/arteks.v3i2.69.

Presiden Republik Indonesia. 1990. UndangUndang Republik Indonesia Nomor 9 Tahun 1990 Tentang Kepariwisataan. Indonesia.

Purbadi, Yohanes Djarot. 2010. 'Tata Suku Dan Tata Spasial Pada Arsitektur Permukiman Suku Dawan Di Desa Kaenbaun Di Pulau Timor'. Disertasi. https://doi.org/10.13140/RG.2.2.18372.32640

Purbadi, Yohanes Djarot, Achmad Djunaedi, and Sudaryono. 2019. 'Kearifan Kaenbaun Sebagai Dasar Konseptual Pada Tata Spasial Arsitektur Permukiman Suku Dawan Di Desa Kaenbaun'. ARTEKS: Jurnal Teknik $\begin{array}{llll}\text { Arsitektur } \quad 3 & \text { (2): } 215-38 .\end{array}$ https://doi.org/10.30822/arteks.v3i2.71.

Purbadi, Yohanes Djarot, and Reginaldo Christophori Lake. 2019. 'Konsep KampungWisata Sejahtera, Kreatif, Cerdas Dan Lestari Berkelanjutan'. EMARA: Indonesian Journal of Architecture 5 (1): 12-23. https://doi.org/10.29080/eija.v5i1.641.

Pusat Bahasa Kemdikbud. 2016. 'Kamus Besar Bahasa Indonesia ( KBBI )'. Kementerian Pendidikan Dan Budaya.

Refranisa. 2019. 'Pola Permukiman Di Dusun Mantran Weran Magelang Dalam Bingkai Kebudayaan Jawa'. ARTEKS : Jurnal Teknik $\begin{array}{llll}\text { Arsitektur } & 3 & \text { (2): } & 159-70 .\end{array}$ https://doi.org/10.30822/arteks.v3i2.67.

Ritchi, Hamzah, Reza M Zulkarnaen, Zulyan Dewantara, Departemen Akuntansi, Fakultas Ekonomi, and Universitas Padjadjaran. 2018. 'Pemanfaatan Teknologi Informasi Dalam Upaya Peningkatan Aksesibilitas Ukm (Desa Wisata) Kepada Pasar Di Lokasi Wisata Pangandaran Dan Sekitarnya'. Pengabdian Kepada Masyarakat.

'Rumah Adat (Omo Lasara/Omo Hada) Hilinawalo Mazino'. 2014. Blogspot. 2014. https://luahahassan.blogspot.com/2014/.

Salura, Purnama, and Reginaldo Christophori Lake. 2014. 'The Architectural Language of Inner and Outer Space as Observed among the Atoni Tribe in the Tamkesi Kampong on Timor Island'. International Journal of Academic Research 6 https://doi.org/10.7813/2075-4124.2014/63/a.29.

Syuaib Intan, Muhammad Fadhlan, and Nasruddin Nasruddin. 2019. "“OMO HADA” Arsitektur Tradisional Nias Selatan Diambang Kepunahan'. KALPATARU 27 (2): 105. https://doi.org/10.24832/kpt.v27i2.458.

Yuliana K, Kartika, and Rina Kurniati. 2013. 'UPAYA PELESTARIAN KAMPUNG KAUMAN SEMARANG SEBAGAI KAWASAN WISATA BUDAYA'. Teknik Perencanaan Wilayah Kota. 